\title{
A Study on Atmospheric particulates Heavy metals near Thermal power station, Tuticorin, Tamil nadu
}

\author{
Sheebha Malar O V ${ }^{1}$, Isac Sobana Raj $C^{2}$ and Jayasutha T K ${ }^{3}$
}

${ }^{1}$ Department of Chemistry and Research, Nanjil Catholic College of Arts and Science, Kaliyakkavilai, Tamil Nadu, India.629153

${ }^{2}$ Department of Chemistry and Research, Nesamony Memorial Christian College, Marthandam, Tamil Nadu, India. 629165

${ }^{3}$ M.Phil. Scholar, Department of Chemistry and Research Centre, Nesamony Memorial Christian College, Marthandam, 629165

\begin{abstract}
Pollution due to heavy metals like lead cause anemia, convulsions, brain damage, problems in liver, kidney, circulatory and nervous and death. Combustion of fossil fuel is the main source of anthropogenic emission of various trace elements in the atmosphere since coal contains almost all elements in the periodic table. Trace metals are present virtually in all coals with concentrations varying as a function of metal, coal deposit and coal location. The plant design, and particularly the burner configuration, influences the emissions of trace elements into the atmosphere. At a typical peak temperature of 1500 $0 \mathrm{C}$, the volatile trace elements in the coal ash evaporate, and later they condense as sub-micron aerosol particles. Bituminous coal contains more impurities of trace metals than lignite and subbituminous coals. This paper deals with all the study techniques that were involved in the collection of aerosol particles and analysis of chemical composition of particulates for a period of three months from March 2014 to June 2014 in Tuticorin industrial area. The present research was envisaged to cover the objectives to assess the trace metals in the respirable suspended particulate.
\end{abstract}

Keywords: Toxic metals, pollution, health effect, pollutants

\section{Introduction}

There are now growing concern all over the world about respirable particulate matter of size $10 \mu \mathrm{m}$ and less. World Health Organization (WHO) has classified these particles as thoracic particles because these are respirable due to their small size and are lodged deep down into the lower respiratory tract.
These fine particles contain most of the toxic trace elements. In this research work, an attempt has been made to study the concentration of some of the environmentally important trace elements including heavy metals $(\mathrm{Cu}, \mathrm{Fe}, \mathrm{Zn}, \mathrm{Cd}, \mathrm{Pb}, \mathrm{Hg}$ and $\mathrm{As})$. The sources of these fine particles are due to anthropogenic activities like coal-fired power plants, industrial boilers, diesel exhaust, wood burning, garbage incineration, etc. Tuticorin Thermal Power Station (TTPS) which consumes tons of coal $(\sim 17000$ to 18000 tons $)$ per day is the major source for the discharge of trace metals into the atmosphere of Tuticorin. Recent studies on the behavior of trace metals in the environment have concluded that many of these components create serious problems due to their toxicity and bioaccumulation in various environment compartments. Several of these compounds are ubiquitous in various raw materials and industrial products. Many trace metals evaporate from raw materials during the production of Industrial goods and during the consumption of fuels, ores, etc., incineration processes, and application of various chemicals. While emitted into the atmosphere many trace metals are subjected to long-range transport within air masses and they migrate through the ecosystem. Tuticorin, an industrial city falls near the coastal region, the Bay of Bengal, and such pollution studies are gaining importance due to the Gulf of Mannar Biosphere Reserve, an environmentally fragile area.

\subsection{Study Area}

Tuticorin district is a part of South Tamil Nadu, India. Located in the southeastern corner of Indian 
Peninsular between $8^{\circ} 35^{\prime} 12^{\prime \prime}$ and $8^{\circ} 40^{\prime} 10^{\prime \prime} \mathrm{N}$ and $78^{\circ} 3^{\prime} 90^{\prime \prime}$ to $78^{\circ} 10^{\prime} 26^{\prime \prime}$ E bound on the North by the districts of Virudhunagar and Ramanathapuram, on the East and Southeast by Gulf of Mannar, West and Southwest by Tirunelveli district. The study area falls in the Survey of India topo sheet no, 58L/1. The climate of this region is hot and dry. This district, particularly in and around Tuticorin, is the major salt producer of the country.

\section{Apparatus}

Respirable particulate sampler, Envirotech APM was used to collect atmospheric aerosol particulates. This High volume sampling is an internationally accepted standard technique for measuring the concentration of suspended particulates in the atmosphere.

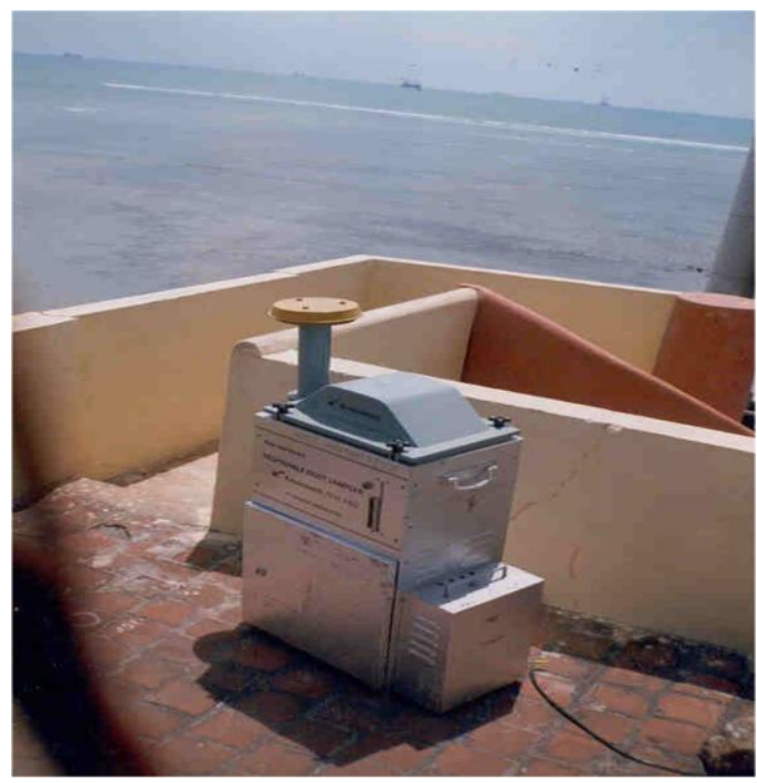

Fig 1 Envirotech APM

A large volume ( 1500 cubic meters) of atmospheric air can be passed through Whatman glass microfibre filter papers over a period of eight hours. Thus measurable amount of dust samples in the area with dust levels as low as one microgram and up to 10 microns were collected for further analysis.

\section{Locations of Air Sampling}

In order to determine the chemical composition of collected aersol particles the sampling area was selected near to the thermal power plant camp - I where a residential area is also located near by the sampling station.

\section{Atmospheric trace elements}

The respirable suspended particulate matter samples were collected on glass micro fiber filter papers. Known area of the filters from the collected samples were cut into small pieces with the help of plastic scissors and treated with a mixture of nitric acid and hydrochloric acid in order to oxidize the organic matter and dissolve the metals present in the sample. The concentrations of the trace elements were measured using ICP-MS and reported in $\mu \mathrm{g} / \mathrm{m}^{3}$.

\section{Analysis}

The concentrations of trace elements were analyzed with the help of ICP-MS. The principle of ICP -MS is, an ICP source consists of a flowing stream of argon gas ionized by an applied radio frequency field typically oscillating at $27.1 \mathrm{M} \mathrm{Hz}$. This field is inductively coupled to the ionized gas by a watercooled coil surrounding quartz "torch" that supports and confines the plasma. A sample aerosol is generated in an appropriate nebulizer and spray chamber and is carried into the plasma through an injected tube located within the torch. The sample aerosol is injected directly into the ICP, subjecting the constituent atoms to temperatures of about 6000 to $8000 \mathrm{oK}$. Because this results in almost complete dissociation of molecules, significant reduction in chemical interferences is achieved. The high temperature of the plasma excites atomic emission efficiently. Ionization of a high percentage of atoms produces ionic emission spectra. The ICP provides an optically "thin" source that is not subject to selfabsorption except at very high concentrations. Thus, linear dynamic ranges of four to six orders of magnitude are observed for many elements. The efficient excitation provided by the ICP-MS results in low detection limits for many elements. This coupled with the extended dynamic range, permits effective multi element determination of metals.

The samples were aspirated and directly fed into ICP-MS and the absorbance was recorded. Mercury, arsenic, and selenium were done by vapor generation technique. Mercury was generated as elemental mercury, whereas arsenic and selenium were generated as their hydrides. The metal concentrations were calculated in comparison with the standards. All the determinations were based on replicate analysis to avoid error.

\section{Calculations}

The metal concentrations were calculated by the following formula 
$\mu \mathrm{g}$ metal $/ \mathrm{m}^{3}=\frac{(\mathrm{C} \times \mathrm{A})-\mathrm{B}}{\mathrm{V} \times \mathrm{F}}$

Where

$\mathrm{C}=$ concentration $(\mu \mathrm{g}$ metal $/ \mathrm{mL})$ in the aliquot

$\mathrm{A}=$ volume of aliquot $(\mathrm{mL})$

$\mathrm{B}=$ total $\mu \mathrm{g}$ of metal in the Blank

$\mathrm{F}=$ fraction of total sample in the aliquot used for measurement

$\mathrm{V}=$ volume of air sampled.

\section{Results and discussion}

In the last few decades, environmental pollution due to toxic as well as heavy metals has been on the rise in some states of India due to open mining of different types of ores, industrial emissions (Woodcock, C. E.et.al,1990) and road transport. World Health Organization (WHO, 2002) points out that outdoor air pollution contributes as much as 0.6 to $1.4 \%$ of the burden of disease in developing regions, and other types of pollution, such as lead in water, air, and soil, may contribute $0.9 \%$. Several cations have their positive and negative effects on human beings and environment (Vakeva, M,2000). The various metals present in particulate matter play an important role as activator for the enzymaticcatalysis processes in human beings like $\mathrm{Fe}$ and $\mathrm{Zn}$ ( Zheng, M., Fang, M ,2000) and they are essential for human health and serve as catalysts for fat oxidation.

High temperature processes, such as coal and oil combustion in electric power plants and industrial plants, roasting and smelting of ores in nonferrous metal smelters, melting operations in ferrous foundries, refuse incineration, kiln operations in cement plants etc emit various trace metals into the atmosphere. The amount of these emissions depend on the contamination of fossil fuels and raw materials, physical and chemical properties of trace metals, affecting their behavior during the industrial processes and the type and efficiency of control equipment used (Schroeder, W. H,et.al, 1987). The studies on the behavior of trace metals in the environment have concluded that many of the trace elements create serious problems due to their toxicity and bioaccumulation in various environmental compartments (Saric, M, 1991).

In the present study seven elements copper (as $\mathrm{Cu}$ ), Iron (as Fe), Mercury (as Hg), Zinc (as Zn), Lead (as $\mathrm{Pb}$ ), Arsenic (as $\mathrm{As}$ ), and Cadmium (as $\mathrm{Cd}$ ) were studied and the results are shown in the Table1.
Table 1:Trace metals in the air borne particulates

\begin{tabular}{|c|c|c|c|c|}
\hline $\begin{array}{c}\text { S. } \\
\text { No }\end{array}$ & Parameter & Protocol & $\begin{array}{c}\text { Con. in } \\
\text { the } \\
\text { RSPM }\end{array}$ & $\mu \mathrm{g} / \mathrm{m} 3$ \\
\hline 1 & $\begin{array}{c}\text { Copper (as } \\
\mathrm{Cu})\end{array}$ & $\begin{array}{c}\text { IS 5182 (part-22: } \\
\text { 2004/ICPMS }\end{array}$ & $15.9 \mu \mathrm{g}$ & 0.03 \\
\hline 2 & Iron (as Fe) & $\begin{array}{c}\text { IS 5182 (part-22: } \\
\text { 2004/ICPMS }\end{array}$ & $307 \mu \mathrm{g}$ & 0.59 \\
\hline 3 & $\begin{array}{c}\text { Mercury (as } \\
\mathrm{Hg})\end{array}$ & $\begin{array}{c}\text { IS 5182 (part-22: } \\
\text { 2004/ICPMS }\end{array}$ & $0.001 \mu \mathrm{g}$ & $\begin{array}{c}\text { Below } \\
\text { deductible }\end{array}$ \\
\hline 4 & $\begin{array}{c}\text { Zinc (as Zn) } \\
\text { IS 5182 (part-22: } \\
\text { 2004/ICPMS }\end{array}$ & $500 \mu \mathrm{g}$ & 0.95 \\
\hline 5 & $\begin{array}{c}\text { Lead (as Pb) } \\
\text { IS 5182 (part-22: } \\
\text { 2004/ICPMS }\end{array}$ & $9.9 \mu \mathrm{g}$ & 0.019 \\
\hline 6 & $\begin{array}{c}\text { Arsenic (as } \\
\text { As) }\end{array}$ & $\begin{array}{c}\text { IS 5182 (part-22: } \\
\text { 2004/ICPMS }\end{array}$ & $0.7 \mu \mathrm{g}$ & 0.001 \\
\hline 7 & $\begin{array}{c}\text { Cadmium(as } \\
\text { Cd) }\end{array}$ & $\begin{array}{c}\text { IS 5182 (part-22: } \\
\text { 2004/ICPMS }\end{array}$ & $9.9 \mu \mathrm{g}$ & 0.019 \\
\hline
\end{tabular}

\subsection{Copper}

Copper in the atmosphere comes from a wide variety of natural and anthropogenic sources. The important anthropogenic sources of pollutant copper in the atmosphere are copper production and handling, iron and steel production and fossil fuel combustion (Rotstayn, L. D,et.al,2000).

In addition to the influence of the local sources, the copper in the ambient air at any given location will also depend on the local soils, and the copper import from distant sources. In India, the highest concentration was reported in Jhunjhunu as $4.7 \mu \mathrm{g} / \mathrm{m} 3$ during the summer season(Rosenfeld, D. ,1999).

Present study shows an average concentration of copper $0.03 \mu \mathrm{g} / \mathrm{m} 3$, during summer season. Since the sampling station is near by the Thermal power plant most of the copper source may be attributed to the thermal power plant and among the other natural sources like soil dust and other anthropogenic activities.

\subsection{Iron}

Iron is the most abundant naturally and it is second in abundance after aluminum among all the metals in earth's crust(Orchek, J., 1976).

The results indicate that highest monthly average concentration $0.59 \mu \mathrm{g} / \mathrm{m}, 3$ was during the study period (March - May). Since the study has been conducted during hot weather season, most of the Iron could be attributed to the crustal origin in addition to the anthropogenic activities such as coal burning and other high temperature processes. 


\subsection{Mercury}

Mercury is known to be a toxic heavy metal which exists in three chemical states. Viz., elemental mercury $(\mathrm{Hg} \mathrm{o})$, mercurous $(\mathrm{Hg}+)$, and mercuric $(\mathrm{Hg}++)$. It forms both inorganic and organic compounds (WHO, 1990). Metallic mercury pollution is produced from mining operations, smelters, combustion of fossil fuel, and refining of gold. Mercury is used in large quantities in the chloralkali industry for the production of chlorine and caustic soda through the electrolysis of brine (sodium chloride solution). Approximately $80 \%$ of the inhaled mercury vapor is absorbed in the lungs. Dissolved elemental mercury is transported in blood and distributed to different organs like brain, kidney, thyroid gland, pituitary gland, liver, ovaries, pancreas, prostate and testes. It easily passes the placental and brain barriers as well as the erythrocyte membrane.

Mercury emissions into the atmosphere can be roughly classified into those due to natural processes and those due to human activities. Mercury evaporates itself owing to the use of metallic mercury and from mercury containing compounds through heating and combustion processes. Most mercury emitted is due to the combustion of fossil fuels, and other industrial manufacturing processes, compost incinerators, mining and extraction of mercury from cinnabar, the chloralkali industries, paper pulp, paints, fungicides, electrical equipment, instrumentation, and amalgamation,( Nakajima, T,2001).

Present study, records a trace level of mercury and almost below deductible limit. During high temperature anthropogenic processes, the volatile elements such as mercury are removed from the concentrate and remain with the flue gases. All the mercury in the smelter will vaporize early in the process (Molnar, A., 1993).

\subsection{Zinc}

Zinc is also one of the most abundant element in the earth's crust. The rock forming minerals contain an average of about $70 \mathrm{ppm}$ of zinc. The content of zinc in soil is highly variable, averaging about $54 \mathrm{ppm}$. It is generally higher near industrial area or highways due to the emission from tire wear. It is also associated with naturally occurring organic acids such as humic and fulvic acids. Zinc is an essential metal, has been found in every tissue, and is the second most abundant trace metal in the human body. Occupational inhalation exposure to zinc is in the form of $\mathrm{ZnO}$ and is associated with metal fume fever. The symptoms associated with this syndrome include fever, chills, dyspnea, muscle soreness, nausea, and fatigue (NIOH, 1975).
Zinc, one of the anthropogenic trace metals tend to concentrate on fine particulates, have a long resident time in the atmosphere and shall be transported to longer distance. The anthropogenic emission sources, such as coal burning, may pose substantial impacts not only to the surrounding area but also to the remote environment (Marshall, B. T,1986).

Above Table 1 shows that an average concentration of $0.95 \mu \mathrm{g} / \mathrm{m} 3$ of Zinc in Tuticorin during the study period.

\subsection{Lead}

Lead has widespread industrial usage and continual release into the environment as an exhaust emission, has made lead one of the most studied heavy metals. Humans are exposed to lead in the occupational setting by inhalation and through contaminated foods and tobacco. Heavy exposure of lead may occur in lead smelters, metal scrapping, spray-painting, and storage battery manufacturing (U. S. EPA, 1986). The alkyl lead compounds, tetraethyl-and tetra methyl lead are widely used as antiknock agents in gasoline (up to $1 \mathrm{~g} / \mathrm{lit}$ ) although their use has decreased dramatically in many countries during the last two decades(Kato, N., and Akimoto, H,1992).

Exposure to lead may cause symptoms and signs from both the peripheral and central nervous systems. The peripheral nervous system damage causes paralysis, as well as pain in the extremities. Several studies have shown that chronic lead exposure reduces nerve conduction velocity in peripheral nerves in adult's subjects without clinical symptoms and signs of disease. In children, lead exposure may cause encephalopathy, with ataxia, coma, and convulsions .

The average concentration of lead as $\mathrm{Pb}$ is reported as $0.019 \mu \mathrm{g} / \mathrm{m} 3$. The main source of its origin of exhaust emission from automobiles. However, emissions of $\mathrm{Pb}$ could arise from waste incinerators due to the use of their metal oxides as pigments, stabilizers, and catalysts in plastic processing.

\subsection{Arsenic}

Environmental arsenic contamination occurs mainly from industrial processes such as smelting of metals, application of arsenical pesticides, herbicides, and power generation from coal or geothermal sources. The burning of coal and smelting of metals are major sources of arsenic in air. Air borne arsenic can be transported over long distance in the atmosphere before being precipitated(Katherine Healey ,2005).

The most common inorganic arsenic in air is arsenic trioxide. Trivalent arsenites are more toxic than pentavalent arsenates. Its extreme toxicity is attributed to its potent hemolytic activity causing severe hemolytic anemia followed by acute renal failure. Arsenic dust or fumes cause nausea, and 
vomiting, in smelter workers (Crocker, B. B., Schnelle, K. B. , 1998).

A large number of epidemiological studies have shown that inorganic arsenic, in the air increases the risk of lung cancer. The residents living near smelters or arsenic chemical plants may increase the risk of lung cancer. Arsenic in the atmosphere has both natural and anthropogenic sources(Dejmek, J., 1999).

The results of arsenic demonstrate that monthly average of $0.001 \mu \mathrm{g} / \mathrm{m} 3$ has been recorded during the study period. The aerosol particles formed during smelting operations in a copper smelter would be extremely small $(0.001-10 \mu \mathrm{m})$ The PM10 particles formed act like gases and this can be carried much farther from source. These air borne particles formed are carried by wind and represented in the sampling locations. In a power plant using coal as raw material, arsenic is captured in the fly ash and behaves generally the overall behavior of a particulate matter of the power station. The collection efficiency in electrostatic precipitator (ESP) control equipment is lower for submicron particles than for larger particles while arsenic concentrations are often significantly higher in the submicron particles. Thus, the deposition of submicron particles in the down wind environment may represent a risk of arsenic migration. Combustion of residual fuel oil commercial boilers also discharges arsenic(Charlson, R. J. , 1992).

The highest average concentration of $0.064 \mu \mathrm{g} / \mathrm{m} 3$ arsenic in Shyambazar Crossing, Calcutta, India has been reported during 1993 .

\subsection{Cadmium}

The primary sources of cadmium contamination within the environment include mining, refining, and smelting operations. Additional sources include fossil fuel consumption, municipal waste incineration, agricultural use of sewage sludge and phosphate fertilizers, and other uses such as batteries, alloys, paints, and plastics. Mechanical processes generate cadmium dusts whereas heating can generate cadmium fumes during metal smelting and processing or during electroplating. Industries utilizing large quantities of cadmium, such as in the production of nickel/cadmium batteries, can also represent sources of high exposure. Cigarette smoking is also a major route for human exposure since cigarette may contain $1-2 \mu \mathrm{g}$ of $\mathrm{Cd}$ and inhalation exposure is a highly efficient mode for cadmium entry into the body. Cadmium has an extremely long biological half-life, which essentially makes the metal a cumulative toxin. It gets accumulated primarily in the liver and kidney. Cadmium intoxication can also affect calcium homeostasis and has been associated with the debilitative disease called "Itai-Itai", first observed in a group of Japanese women exposed to cadmium and characterized by severe osteoporosis (Burnett, R. T., 1977).

The present study in Tuticorin Table 4 recorded an average concentration of $0.019 \mu \mathrm{g} / \mathrm{m} 3$ of cadmium during the study period.

Consolidated results shows that trace metals are present in the particulates of Tuticorin. The wind speed, high temperature, and low humidity facilitate to carry the pollutants to a long distance away from the source. reported maximum concentration of elemental pollution during summer seasons in their studies. This study is also carried out in the summer season. The shifting winds in Tuticorin, which is a coastal area, will mix up various types of aerosol particle from different sources, which enhance the secondary reaction in the boundary layer. This phenomenon put difficulty in ascertaining the actual source of pollution.

\section{CONCLUSION}

The RSPM collected on filter paper are subjected to chemical analysis using ICP-MS. The trace elements are constantly introduced into the Tuticorin urban atmosphere as pollutants due to growing industrial activities. High temperature processes in the study area, such as coal and oil combustion in electric power plant, and other industrial plants; emit various trace metals along with other pollutants. The occurrences of toxic metals in the ambient atmosphere of the study area as chemical contaminants and the potential human exposure to these chemicals with the associated toxicological impacts require future studies. The contribution of metals to the respiratory tract cancer has been presented. The occurrences of toxic metals in the ambient atmosphere as chemical contaminants and the potential human exposure to these chemicals with the associated toxicological impacts have been receiving increasing attention. Study on the distribution of trace elements in the ambient atmosphere of Tuticorin industrial area will help us to understand if there is any toxic heavy element in the atmosphere which poses health effects to the human population and to design the possible control measures. Appropriate planning shall be done before commissioning any industrial establishments to isolate the human population from direct hit by pollutants. Hospitals, schools, and dwelling complexes have to be located away from pollution sources and these may be established at places after carefully studying the meteorological aspects and the pattern of dispersion of air pollutants. 


\section{References}

[1] Burnett, R. T., Cakmak, J. R., Krewski, D. The role of particulate Ambient Air pollution and Hospitalization for Cardio respiratory disease. Environ. Health perspect. 105, 614-620 (1997).

[2] Charlson, R. J. Climate forcing of anthropogenic aerosols. Science, 255, 423430 (1992).

[3] Crocker, B. B., Schnelle, K. B. Air pollution control for stationary sources: In Encyclopedia of Environmental analysis and Remediation (Ed) Robert, A. Mayers, John Wiley \& Sons, Inc., New York, Vol-I (1998).

[4] Dejmek, J., Selvan, S. G., Benes, I., Solansky, I., Sram, R. J. Fetal growth and parental exposure to particulate matter during gestation. Environ Health Perspect. 107, 475 - 480 (1999).

[5] Katherine Healey . Genotoxicity of size fractionated samples of urban particulate matter 45 380-387. (2005)

[6] Kato, N., and Akimoto, H. Anthropogenic emission of $\mathrm{SO} 2$ and $\mathrm{NOx}$ in Asia, Emission inventories Atmos. Environ, 26, 2991-3017, (1992).

[7] Marshall, B. T., Patterson, E. M., and Grams, G. W. Characterization of the Atlanta area aerosol, Elemental composition, and possible sources. Atmos. Environ. 20 (6) 1291-1300, (1986).

[8] Molnar, A., Meszaros, E., Bosol, L., Borbely-Kiss, I., Roltay, E., Sazbo, G. Elemental composition of atmospheric aerosol particles under different conditions of Hungary, Atmos. Environ. 27 (A) 24572461, (1993).

[9] Nakajima, T. A possible correlation between satellite-derived cloud and aerosol microphysical parameters. Geophys. Res. Lett. 28, $1171-1174$ (2001).

[10] Orchek, J., Massuri, J. P., Gayrand, P., Grimand, C., and Charpin, J. Effect of Short-term, low level nitrogen dioxide exposure on bronchial sensitivity of asthmatic patients. J. Clin. Invest, 57, 301307. (1976).

[11] Rosenfeld, D. TRMM observed first direct evidence of smoke from fossil fires inhibiting rainfall. Geophys. Res. Lett. 26, 3105-3108, (1999).

[12] Rotstayn, L. D., Ryan, B. F., and Penner, J. E. Precipitation changes in a GCM resulting from the indirect effect of anthropogenic aerosols. Geophys. Res. Letts. 27, 30453048 (2000).

[13] Saric, M. In Encyclopedia of Occupational Health and Safety, 3rd ed., (Ed.) Parmeggiani, L. International Labor office, Geneva, 2, 1279 (1991).

[14] Schroeder, W. H., Dobson, M., Kane, D. M., and Johnson, N. D. Toxic trace elements associated with air borne particulate matter: A review. J. Air Pollut. Control. Assoc. 37, 1267- 1285 (1987).

[15] Vakeva, M., Puhakka, T., Nilson, E. D., Holiti, H., Makela, J. M. Effects of meteorological processes on aerosol particle size distribution in an urban background area. J. Geophys. Res. 105, 9807-9821, (2000).

[16] Woodcock, C. E., Sham, C. H., and Shaw, B. Comments on selecting a Geographical information system for Environmental management 14 (3), 307-315 (1990).

[17] Zheng, M., Fang, M Correlations between Organic and Inorganic Species in Atmospheric Aerosols Environ. Sci. Technol. 2000, 34, 2721-2726. 